\title{
The Drosophila genes disconnected and disco-related together specify development of adult legs
}

\author{
Juan B. Rosario ${ }^{1,2}$ and James W. Mahaffey ${ }^{1 *}$
}

${ }^{1}$ Department of Biological Sciences and Program in Genetics, North Carolina State University, Raleigh North Carolina, United States of America

${ }^{2}$ Current address: Integra Labs, Durham North Carolina, United States of America

*Corresponding author: mahaffey@ncsu.edu

Running Title: Drosophila leg disco/disco-r

Keywords: Drosophila, appendage, disco, leg, Distal-less 


\begin{abstract}
In the fruit fly, Drosophila melanogaster, specification of the legs begins during embryogenesis when Wingless signaling induces small groups of cells to form the imaginal disc primordia in the thoracic segments. This signal initiates expression of transcription factors that will later be used to pattern the legs. The paralogous genes disconnected and disco-related encode transcription factors that are expressed in the disc primordia during early embryogenesis, and their expression continues in the leg discs during larval and pupal stages. The importance of these two genes in establishing the leg development trajectory was indicated by our previous observation that ectopic expression of either gene in the wing discs cells caused legs to develop in place of wings. However, because of their redundancy and requirement for survival during embryogenesis, we were unable to define their role in development of the adult legs. Here, we report loss-offunction analyses of the disco genes during development of the legs. We discovered that loss of both genes' functions causes both truncation of the distal leg with apparent overgrowth of proximal regions and complete loss of legs and ventral thoracic body patterning. At the molecular level we noted reduction or loss of signaling and transcription factors that pattern the proximal-distal axis of the legs. We conclude from these studies that the disco genes promote leg development through regulation of signaling processes, but also by stabilizing expression of the leg determination gene network.
\end{abstract}




\section{INTRODUCTION}

In holometabolous insects, those that undergo complete metamorphosis such as Drosophila melanogaster, most adult body structures develop from imaginal discs, groups of cells that are set-aside during embryogenesis, proliferate during larval stages, and form the appendages (mouthparts, legs, wings, halteres, antennae, etc.) and body wall of the adult insect during the pupal stage. The thoracic imaginal discs form during embryogenesis when segmental expression of the morphogen Wingless (Wg) induces a small group of cells to activate appendage-specific gene networks (Cohen et al., 1993; Cohen, 1990; Estella and Mann, 2010; Estella et al., 2003). The dorsal limit of the disc primordia is set through repression by Decapentaplegic (Dpp) and the ventral limit by repression from the Epidermal Growth Factor Receptor (EGFR) (Cohen et al., 1993; Goto and Hayashi, 1997; Kubota et al., 2000; Raz and Shilo, 1993).

Shortly after induction, the thoracic disc primordia separate into the dorsal (wings and halteres) and ventral (legs) imaginal precursors (Cohen et al., 1993). As the dorsal and ventral disc primordia separate, changes in gene expression occur that begin the process of patterning the adult legs; the current model is summarized in Fig. 1. Cells in the posterior compartment of the leg discs express engrailed (en), which activates hedgehog $(h h)$ signaling. Cells just anterior to the posterior compartment border receive this Hh signal and respond by activating either $d p p$ if dorsal or wg if ventral (Basler and Struhl, 1994; Brook and Cohen, 1996; Brook et al., 1996; Jiang and Struhl, 1996; Lecuit and Cohen, 1997; Mohler, 1988; Tabata et al., 1992; Tabata and Kornberg, 1994; Theisen et al., 1996). In this manner the overall axes of the discs and of the adult legs are determined. Cells in the center of the disc perceive high collective concentrations of $\mathrm{Wg}$ and Dpp and initiate expression of Distal-less (Dll) (Fig. 1B). Although Dll is expressed throughout the thoracic disc primordia during initiation in the early embryo, this later $D l l$ expression is restricted to cells that will form the medial-to-distal portion of the legs (Angelini and Kaufman, 2005; Bolinger and Boekhoff-Falk, 2005; McKay et al., 2009; Panganiban, 2000b). Cells in the outer region of the discs do not respond to the $\mathrm{Hh}, \mathrm{Wg}$ and Dpp signals, and these cells activate genes necessary for proximal identities, genes such as homothorax (hth) and teashirt (tsh) (Diaz-Benjumea et al., 1994; Estella et al., 2012; Gonzalez-Crespo et al., 1998; Gonzalez-Crespo and Morata, 1996). Cells that lie 
between these two domains express dachshund ( $d a c)$, which defines the medial region (Giorgianni and Mann, 2011; Mardon et al., 1994). In this manner three major proximal to distal domains of the adult leg are established in the larval imaginal discs. The Hth/Tsh domain determines the body wall and the most proximal segment of the leg (the coxa); Dll specifies the distal portion of the leg, and Dac the medial.

Other genes are expressed in the imaginal discs primordia during early embryogenesis, such as the paralogous pair disconnected (disco) and disco-related (disco-r) (Cohen et al., 1991; Lee et al., 1991; Mahaffey et al., 2001), together referred to as "the disco genes" hereafter. The disco genes encode redundant $\mathrm{C} 2 \mathrm{H} 2$ zinc finger transcription factors (Mahaffey et al., 2001). They are initially expressed in the thoracic disc primordia during embryonic stage 11 (Cohen et al., 1991; Lee et al., 1991; Mahaffey et al., 2001), and they are continually expressed in the ventral imaginal discs after separation of the dorsal discs precursors. By late third instar the disco genes are expressed throughout most of the cells of the leg imaginal discs, encompassing the Dll and dac domains and extending into more proximal regions (Patel et al., 2007). The importance of the disco genes during leg specification was demonstrated by ectopic expression experiments. Expression of either gene in the wing discs causes these discs to form legs (Patel et al., 2007). However, what role these genes have during normal leg development remained elusive, since loss of both genes is lethal to embryos, and randomly generated clones of cells lacking both genes are rarely recovered in the leg discs (Patel et al., 2007). Below we describe results of our investigation into the role of the disco genes during development of the Drosophila legs. We conclude that these genes are necessary to stabilize leg development, likely through stabilization of the leg transcriptional network.

\section{MATERIALS AND METHODS}

Fly stocks: Oregon-R was used as a wild type. The following fly lines were obtained form the Bloomington Stock Center: $D f(1)$ ED7355 (FBst0008899, Ryder et al., 2004); tubP-GAL80 ${ }^{\text {ts }}$ (FBst0007108, McGuire et al., 2003); the disco-r RNAi line $y$ [1] $s c[*] v[1] ; P[y[+t 7.7] v[+t 1.8]=T R i P . H M S 02247] a t t P 2$ from the Transgenic RNAi Project (FBst0041683); Act5C-Gal4 (FBst0004414); Dll ${ }^{m d 23}$ (FBst0003038, Calleja et al., 
1996). We used several lines carrying the disco $^{l}$ allele (Fischbach and Heisenberg, 1984), one from A. Campos (McMaster University), one from J. Hall (Brandeis University) and one from the Bloomington Drosophila Stock Center (FBst0005682). Three additional disco-r RNAi lines were obtained from the Vienna Drosophila RNAi Center (VDRC), P[KK103892] VIE-260B (FBst0473452), w[1118]; P[GD13583]v35750 (FBst0461319), w 11118]; P[GD13583]v35751 (FBst0461320). UAS-GFP/UAS-GFP was a gift from Dr. Patricia Estes, North Carolina State University. Flies were raised on standard cornmealagar-molasses media at $17^{\circ} \mathrm{C}$ except where otherwise required by the experiment.

Fly crosses to generate disco-lof: To generate disco $^{1} /$ disco $^{1}$; disco-r RNAi/disco$r$ RNAi flies, we crossed females homozygous for disco $^{l}$ to males Sco/ CyO, Act-GFP. We selected male $\operatorname{disco}^{1} / \mathrm{Y} ;+/ C y O$, Act-GFP and crossed these to disco $^{l}$ homozygous females. We selected females disco ${ }^{1} /$ disco $^{1} ; \mathrm{CyO}$, Act-GFP/+ and crossed them to males homozygous for disco-r RNAi line, $P[K K 103892] V I E-260 B$. From this cross we selected males disco $^{I} / \mathrm{Y}$; disco-r RNAi /CyO, Act-GFP and crossed these to disco ${ }^{l} /$ disco $^{l}$; $\mathrm{CyO}, \mathrm{Act}-\mathrm{GFP} /+$ females. Pair matings of the $C y O$, Act-GFP progeny were set up, and once larval activity was noted in the vial, DNA was extracted from the parents and amplified to verify the presence of the RNAi construct in both parents using the primer sequences recommended by the VDRC. To activate the disco- $r$ RNAi, disco ${ }^{l} /$ disco $^{l}$; disco-r RNAi/disco-r RNAi females were crossed to +/Y; Act-Gal4/CyO, Act-GFP. Non-GFP male larvae were selected by the presence of the testis. In some cases we used tub-Gal80 $0^{\text {ts }}$ to repress the Gal4 system until larval stages (McGuire et al., 2003).

Testing other RNAi lines and an additional Gal4 driver. For Dll-Gal4 activation of the RNAi, we generated a Dll-Gal4, tub-Gal80 fly line by recombination of $P[w[+m W . h s]=G a w B] D l l[m d 23]$ with $w[*] ; P[w[+m C]=t u b P-G A L 80[t s]] 10$. These flies were crossed to homozygous disco $^{1}$ females to generate $\operatorname{disco}^{1} / \mathrm{Y}$; Dll-Gal4, tubGal80 $^{t s} /+$ flies, which were crossed to the disco ${ }^{l} /$ disco $^{l}$; disco- $r$ RNAi/disco-r RNAi. To test different disco-r RNAi constructs, disco ${ }^{1} /+$; Dll-Gal4, tub-Gal80 ${ }^{\text {ts }} /+$ females were crossed with males homozygous for the disco-r RNAi and male adults or pharate adults were scored. We tested two additional disco-r RNAi lines from VDRC, GD35750 and GD35751, and a disco- $r$ RNAi line from the Transgenic RNAi Project (TRiP). 
Growth conditions for disco-lof: Eggs were collected for two days at $17^{\circ} \mathrm{C}$ and then the adults removed. Four days later the progeny were transferred to $30^{\circ} \mathrm{C}$ to inactivate the $t u b-G a l 80^{t s}$. Pharate adults (in this case males) were dissected from the pupal case and along with the eclosing males, were stored in $70 \%$ ethanol. For molecular analysis we followed a similar time regimen, dissecting discs from late third instar male larvae. RNAi and sibling wild type discs were collected together for in situ and immunostaining. We left a portion of the gut attached to the control carcasses to distinguishing them from the disco-lof. Note, $t u b-G a l 80^{t s}$ was not required to pass embryogenesis with Act-Gal4; however, we followed the same timing for elevating the temperature with the Act-Gal4 and Dll-Gal4 larvae. Others and we have noted a slight affect on leg development with the Dll-Gal4 driver since the Gal4 insertion compromises the Dll gene (Calleja et al., 1996; Grubbs et al., 2013). This was taken into account in all analyses.

Determination of $\operatorname{disco}^{1}$ viability: To determine the viability of $\operatorname{disco}^{l}$, we collected males and females of three different disco ${ }^{l}$ lines (see Fly stocks, above) and allowed them to mate for 48 hours. We transferred the parents to a collection cup with a grape agar plate for 18 hours. We collected 200 embryos from these plates, and transferred them to fresh grape agar plates and allowed 28 hours for the larvae to hatch. Un-hatched embryos were cleared for cuticle examination to determine the number of unfertilized or undeveloped eggs. The remaining larvae were transferred to standard food diet and allowed to develop. We counted pupae and adults to determine numbers surviving to each stage. The disco genes were sequenced from all lines to verify they carried the disco $^{1}$ allele.

Molecular analyses: Embryos were collected on grape plates, and larvae for disc dissections were grown on standard Drosophila medium. Fixation of embryos and discs essentially followed that of (Tautz and Pfeifle, 1989). Embryo and larval cuticle analyses followed that described in (Pederson et al., 1996). The single and double fluorescence in situs followed the protocol of (Juarez et al., 2011; Kosman et al., 2004). Antibody detection and double in situ/antibody detection is described in (Heffer et al., 2013). Antibodies used, rabbit anti-Tsh (S. Cohen, IMCB, Singapore); anti-Dachshund, mAbdac2-3 (Mardon et al., 1994); anti-Wingless 4D4 (Brook and Cohen, 1996); anti- 
Beta-gal (Promega); anti-pmad, Phospho-Smad1/5 (Cell Signaling Technology). Dll, disco and $w g$ probes for in situ hybridization were described in Mahaffey et al., 2001). TUNEL analysis was performed using ApopTag® Red In Situ Apoptosis Detection Kit (Millipore) following procedure for whole tissue analysis, but scaled down for Drosophila. Fluorescent stained discs were mounted in 70\% Glycerol, enzymatic detections in Crystal Mount ${ }^{\circledR}$. Images were acquired using a Zeiss LSM 710 confocal microscope system or Zeiss Axioplan microscope with a Q Imaging Micropublisher 5.0 RTV camera. We used ImageJ for quantification of fluorescence (Schneider et al., 2012). Confocal z-stacks were compressed by SUM, and measurements made from three of the brightest regions, standardized by area. p values obtained using JMP version 10 (SAS Institute Inc., Cary NC, USA). For presentations graphics, Adobe Photoshop and ImageJ were used for brightness/contrast adjustments and cropping. All images in each figure were processed identically. Adobe Illustrator was used to assemble the final figures.

\section{RESULTS}

Loss of function phenotypes: To assess the role of the disco genes during development of the adult legs, we eliminated the function of both genes after embryogenesis by combining a null mutation in disco $\left(\right.$ disco $\left.^{l}\right)$ (Heilig et al., 1991) with UAS-driven disco- $r$ RNAi, controlling spatial and temporal activity of the RNAi during development. We refer to this combination as "disco-lof" below. We used two different Gal4 drivers and four different RNAi constructs with comparable results (see Materials and Methods). Note that homo- or hemizygosity for disco $^{l}$ was initially reported to be viable (Steller et al., 1987), but there have been reports that it is lethal (Dey et al., 2009; Glossop and Shepherd, 1998). Therefore, we tested three disco ${ }^{l}$ lines (see Table 1), and found that only the line from the Bloomington Drosophila Stock Center was appreciably less viable than wild type flies. In the present work we used the line we refer to as disco ${ }^{l}$ (C).

We first examined viability and developmental trajectory of the disco-lof progeny from the crosses. We shifted larvae at various times to the non-permissive temperature for $t u b-G a l 80^{t s}\left(30^{\circ} \mathrm{C}\right)$, thus activating the disco-r RNAi. Shifting during first or early second instar resulted in larval death, while shifting during third instar resulted in pharate 
adults with only minor leg defects. Shifting to $30^{\circ} \mathrm{C}$ during second instar (96-144 hrs at $17^{\circ} \mathrm{C}$ ) generated pharate adults with moderate and severe phenotypes, so this timeframe was used for most experiments.

The normal Drosophila leg is composed of five segments (Fig 1C). The body wall and coxa together form the coxapodia, while the trochanter, femur, tibia and tarsus make up the telopodia (Gonzalez-Crespo and Morata, 1996; McKay et al., 2009). The tarsus is further divided into five sub-segments with the pulvilli and claws attached to the most distal of these (t-5). Each leg segment has a characteristic arrangement of bristles, in general organized into longitudinal rows around the circumference of the leg. The bristles have an overall polarity such that most are oriented toward the distal portion of the leg (Hannah-Alava, 1958; Held, 2002; Schubiger et al., 2012; Tokunaga, 1962). On the more distal leg segments, bristles are usually associated with bracts, small, thick trichomes induced by the neighboring bristle. Bristles in the proximal leg segments (up until proximal to mid-femur) are not associated with bracts.

Upon dissecting the disco-lof pharate adults from the pupal cases, we noted two main classes of leg defects. Many pharate adults were missing entire legs, while those legs that formed were abnormal (Fig 2B-D). For those legs that were present, Dll-Gal4driven RNAi usually lacked all tarsal segments and had an enlarged fusion of the proximal segments that appeared to be composed of coxa, trochanter and femur (Fig. 2B,C and Fig. 3B,C). Legs from the Act-Gal4 driver crosses had similar proximal fusions but appeared more severely affected, so it was not possible to distinguish individual coxa, trochanter or femur segments (Fig 2D, and Fig. 3D,E). However, unlike the Dll-Gal4, some tarsal segments and the attached claws were present. We suspect that the differences in phenotype reflect differences in abundance, timing or position of expression of Gal4 drivers. Bristles on the disco-lof legs mostly lacked bracts (Fig. 3), suggesting they were of proximal leg type. In addition, leg bristle polarity was disrupted. The bristles were oriented somewhat randomly, with only small groups similarly aligned (Fig. 3). We confirmed these phenotypic results by removing the disco genes using clonal analysis (data not shown) with the same deficiency we used in our prior work (Patel et al., 2007), but this time targeting the center of the disco-expressing region using the DllGal4 driver to induce FRT recombination. 
When a leg was completely lacking, the ventral body wall was also affected. For example, when a first thoracic leg was absent, the five small microchaetae along the ventral-anterior thorax were also absent (Fig 2B'-E'). When a second thoracic leg was absent, most sternopleural and mesosternal bristles were also absent (Fig. 2 C'-E'). In the most extreme case (Fig 2E) the fly had no legs and no discernable ventral body wall features except for a single bristle, likely a sternopleural.

Morphology of disco-lof leg discs: Defects in the leg imaginal discs were apparent immediately upon inverting wandering third instar larvae. Though variable, the discs were often quite small when compared to those from their wild type siblings (Fig. 4). Wild type leg discs have a typical rounded, teardrop shape with a stalk dorsally (Fig. 4A). Characteristic folds, appearing as rings, demarcate future leg segments or groups of segments. In the center, the "end knob" will give rise to the most distal structures. The most extreme disco-lof discs were small, narrow structures with little obvious morphology (Fig. 4D,E). Less severely affected discs were reduced but retained some segmental folds (Fig. 4C). Some appeared only slightly smaller than wild type (Fig. 4B). The set of discs present in most larvae was a combination of both classes; the number of small versus reduced discs paralleled the number of missing versus truncated legs we observed in the pharate adults. Note, we did not consider rare cases where discs were completely missing, as discs could be torn off inadvertently during the dissections.

Gene expression in disco-lof leg discs: With the reduction in size of the legs and discs, we next examined the accumulation of several gene products that pattern the leg discs, Tsh protein (proximal) and Dac protein (medial) and Dll mRNA (distal) using Oregon-R as controls (see Materials and Methods).

In the most severely reduced discs we did not detect $D l l$ mRNA or Dac protein (data not shown), though we did detect weak staining for the Tsh (Fig. 4E'). We noted that the Tsh-positive nuclei appeared more dispersed than those of the columnar cells in the wild type discs. In less severely affected discs, $D l l$ mRNA was reduced in comparison to wild type (Fig. 5). Even in those discs that were nearly equal in size to wild type controls, Dll mRNA was quite reduced. Dac protein staining was occasionally reduced as well, particularly in smaller discs. We took intensity measurements from the images for all probes (Tsh, Dac and Dll) using three regions of brightest intensity within each disc 
(Fig. 5B). These measurements confirmed that $D l l$ was significantly reduced $(\mathrm{p}=0.00004$, Fig 5), and though Dac appeared to be reduced in some discs, the p value of those shown was just greater than the $5 \%$ probability level $(p=0.06)$. There was no significant difference in Tsh staining between controls and these disco-lof discs.

Dll (Lecuit and Cohen, 1997) and, indirectly, dac (Giorgianni and Mann, 2011) are regulated by Wg and Dpp in the leg discs, and since reduction of either Wg or Dpp can cause truncation of the distal legs, it seemed plausible that expression or function of these morphogens could be altered in these discs. Therefore, we assayed $w g$ transcript and protein and $d p p$ transcript and activity (via p-mad) in disco-lof discs of similar size to those that had reduced $D l l$ mRNA. In control discs $w g$ mRNA and protein accumulate in a wedge-shape sector in the anterior-ventral portion of the leg disc, extending along the disc folds into the posterior compartment (Fig. 6A-A'”'). Wg protein was more widely dispersed than the mRNA (Fig. 6A','). In moderately affected disco-lof discs, wg mRNA did not extending as far anteriorly around the disc and had a sharper boundary along the posterior edge (Fig. 6B-B'). Wg protein (Fig. 6B') was reduced overall and did not appear to spread far from the area of transcript accumulation (Fig. 6B','). By contrast, Dpp transcript and function appeared to be unaffected (data not shown). However, in the most severely affected discs, those that were highly reduced in size, we did not detect either $w g$ (6C-C',') or $d p p$ (data not shown).

Cell Death in disco-lof discs: In our prior report, we proposed that leg disc cells lacking the disco genes may not be viable (Patel et al., 2007). Deletion of leg segments or entire legs and reduced size of the disco-lof leg discs could also indicate that cells of the affected discs have become weakened and may be undergoing apoptosis. To determine if this were the case, we performed TUNEL staining. In disco-lof discs, we observed an increase in TUNEL positive cells compared to wild type (Fig 7A). We noted increased TUNEL staining in disco-lof discs of near normal size and in those severely reduced (Fig 7B,C, respectively). TUNEL stained cells were scattered somewhat randomly throughout the discs. Many were located in the lumen of the disc, suggesting they were extruded from the discs, as is common of apoptotic cells (Rosenblatt et al., 2001). Only an occasional TUNEL positive cell was detected in wild type discs (Fig. 7A). 
Establishment of the leg disc primordia during embryogenesis: Cells of the leg discs primordia are set aside during early embryogenesis; their positions marked by the expression of $\mathrm{Dll}$ (Cohen et al., 1991). A previous study (Cohen et al., 1991) compared disco and $\mathrm{Dll}$ expression in the emerging primordia and concluded that disco was expressed after $\mathrm{Dll}$, and, further, that in the absence of $\mathrm{Dll}$, disco was not activated. However, this was based on expression of the enhancer trap line C50.1S1 to represent disco expression, and we have previously shown this enhancer trap to be inserted into the disco-r gene, not disco (Patel et al., 2007). Therefore, we reexamined Dll and disco expression in early embryos. The thoracic region of wild type embryos at two different stages of development stained to detect disco and Dll mRNAs are shown in Fig 8. Both genes appear to accumulate at stage 10/11 (Fig. 8 A-A','), where their transcripts overlapped in the primordia. We could not detect a difference in their distribution. However, Dll expression is dynamic (Cohen et al., 1993; Estella et al., 2012; Galindo et al., 2011; McKay et al., 2009; O'Hara et al., 1993; Vachon et al., 1992), and, though at this early stage $D l l$ accumulates throughout the thoracic appendage primordia, by late stage 12, Dll transcripts are restricted to what will be the medial to distal portion of the legs. At this stage, disco mRNA was more broadly distributed (Figure 8 B-B','), and this remained the case throughout the rest of development, including in the third instar leg discs (Patel et al., 2007 and data not shown).

Cis-regulatory modules have been identified at the $\mathrm{Dll}$ gene that mimic $\mathrm{Dll}$ regulation (Cohen et al., 1993; Estella et al., 2008; Estella et al., 2012; Galindo et al., 2011; McKay et al., 2009; O'Hara et al., 1993; Vachon et al., 1992). For example, the 304 element is initiated by Wg during stage 10-11 of embryogenesis throughout the thoracic appendage primordia. This enhancer is only active for a brief period. Later, at stage 1213, enhancers such as $L P$ and $L T$ take over. Unlike 304, these enhancers only drive expression in the medial to distal regions of the leg discs (Galindo et al., 2011; McKay et al., 2009) that will become the Dll and dac domains of later leg discs (Estella et al., 2008; Estella et al., 2012).

Given the timing of $L T$ activation and its dependence upon both Wg and Dpp signaling (Estella et al., 2008) we questioned whether $L T$ would react to the loss of the disco gene functions. To test this, we examined $\beta$-galactosidase production by the $L T$ 
reporter in embryos hemizygous for $D f(1) E D 7355$ which deletes both disco and disco-r. At stage 16 in wild type embryos, $L T$ is expressed in a ring of cells in the leg disc primordia (Fig.9 A and see McKay et al., 2009). In embryos hemizygous for $D f(1) E D 7355$, LT expression was weaker and in fewer cells (Fig. 9B). The normal ringshaped pattern was disrupted. We noted no change in the thoracic expression of the 304 reporter in $\mathrm{Df}(1) \mathrm{ED} 7355$ embryos, though interestingly, it was derepressed in some head segments (data not shown).

\section{DISCUSSION}

Appendage development in Drosophila has been extensively studied as a model system to decipher the genetic control of pattern formation during animal development. Previous studies have led to a model whereby signaling systems in the embryo establish the leg primordia, followed by patterned gene expression that establishes the overall axes of the leg and subsequently specifies leg differentiation (see Fig. 1). Previously, we demonstrated that the genes disco and disco-r appear to be major factors in leg development, particularly since ectopic expression of either gene in the wing imaginal disc could induce legs in place of wings (Patel et al., 2007). However, until now we were unable to ascertain the requirement of these genes during development of the adult leg.

Removing the disco gene functions from the second instar onward led to two defects. In the most severe cases, all but the most proximal body wall tissues was missing. Many discs were reduced to thin slivers of tissue having little, if any, accumulation of canonical leg determinants, with the exception that a few cells accumulated Tsh. Since the body wall arises from the peripodial cells and cells from the marginal zone of the discs (the region between the columnar disc cells and peripodial epithelial cells, Fristrom and Fristrom, 1993; McClure and Schubiger, 2005; Milner et al., 1984), and since cells in this marginal zone express the disco genes (Patel et al., 2007, and data not shown), we suspect that these highly reduced discs were incapable of producing any overt appendages, though they may be able to contribute to the body wall of the ventral thorax. Considering our observations, we suggest that the disco genes function as positional determinants, much like $t s h, D l l$ and $d a c$, but having a larger domain that encompasses all but the most proximal portion of the leg disc derivatives. 
Our observations of less severely affected legs and discs were just as informative. Examining these legs and discs indicated that the Disco transcription factors might be necessary to stabilize/maintain the expression of other leg patterning genes, including factors for signaling and transcription, since expression of several genes were not well maintained once the Disco transcription factors were reduced.

It is not clear why the two phenotypes, leg truncations and complete loss, would be present in the same pharate adult. Perhaps this indicates that there were slight differences in efficacy of the disco-r RNAi in different leg discs. If so, this could indicate that level of the residual Disco transcription factors was responsible. However, it could also indicate that there is a change in the requirement of these proteins at about this stage, and indeed, there is a change in gene regulation at this time.

From these studies, we propose that the disco gene products are particularly necessary during transitions in gene expression during leg determination and development. Initiation of the thoracic disc primordia begins at embryonic stage 11, when the segment polarity signal Wg induces small groups of cells in each thoracic hemisegment to express appendage specification genes, such as Dll and the disco genes among others (Cohen et al., 1993; Cohen, 1990; Kubota et al., 2003). It is important to note that at this early stage these groups of cells include the primordia of the ventral (leg) and dorsal (humeral, wings and halters) thoracic discs, and also the larval Keilin's Organs (vestiges of larval legs) (Angelini and Kaufman, 2005; Bolinger and Boekhoff-Falk, 2005; Cohen et al., 1991; McKay et al., 2009; Panganiban, 2000b). Loss of disco and disco-r does not appear to alter the initial induction of the thoracic disc primordia. Indeed, the $D l l$ and disco genes appear to be activated simultaneously, so it would be unlikely that one would be required for induction of the other. Furthermore, loss of the disco genes did not significantly alter expression of the Dll-304 element, which responds to $\mathrm{Wg}$ induction (data not shown).

The first transition occurs at about embryonic stage 14 when the primordia of the ventral and dorsal discs (and the Keilin's organs) separate so that each becomes an independent unit (Bolinger and Boekhoff-Falk, 2005; Cohen et al., 1991; McKay et al., 2009; Panganiban, 2000a). At this time, $D l l$ is repressed in the dorsal thoracic discs and is restricted to only those cells that will form the telopodite region of the leg (the trochanter 
and more distal leg segments) (McKay et al., 2009). Significantly, Dpp signaling is now part of the activation process, where it was repressive during initiation (Campbell et al., 1993; Diaz-Benjumea et al., 1994; Goto and Hayashi, 1997; Kubota et al., 2000; Lecuit and Cohen, 1997). Cells in the leg discs that continue to express Dll must receive high levels of both Wg and Dpp signals (see Figure 1 above). This transition in gene regulation is reflected by changes in enhancer function. For example, the Dll-304 enhancer, which responds to the Wg signaling during induction, is no longer active, and the $L T$ enhancer, in part, directs $D l l$ expression in telopodite region of the leg (Cohen et al., 1993; Estella et al., 2008; Galindo et al., 2011; McKay et al., 2009). Furthermore, the DKO enhancer takes over expression of $D l l$ in the Keilin's organs (McKay et al., 2009). Our observation that, the $L T$ enhancer is not stably expressed in the absence of the disco gene products, indicating that the Disco transcription factors might be necessary to stabilize gene expression orchestrated by $L T$.

A second transition in gene regulation occurs during the late second instar larval stage, when expression of genes such as Dll become independent of Wg and Dpp (72-84 hours after egg laying, Estella et al., 2012; Galindo et al., 2002). This transition is also seen in $D l l$ regulatory modules as the $L T$ enhancer now requires the $M$ element to remain active (Estella et al., 2008; Galindo et al., 2011, reviewed in (Estella et al., 2012). It is around this stage that flies with reduced disco gene products were able to survive long enough to produce the pharate adults, albeit with severe leg defects.

Whether the changes in gene expression in the disco-lof leg discs reflect direct regulation of genes by the Disco transcription factors will need to be addressed in the future. Interestingly, in the study by Negre et al. (2011), Disco binding sites were found near Dll, dac, and $w g$, and though no Disco binding sites were reported in the Dll-LT enhancer, we have discovered sequences in this element that closely resemble those bound by the Disco protein (Rosario and Mahaffey, unpublished). Further work will be necessary to determine whether these genes are direct targets of Disco and Disco-r.

Our loss of function analyses continue to show that the Disco proteins are major factors of the Drosophila leg and ventral appendage development pathway. These genes are members of a conserved family of genes encoding zinc finger transcription factors with homologs found in many animals (Knight and Shimeld, 2001). Considering the 
structural conservation, it is reasonable to ask whether the homologs have similar developmental roles. Indeed, our earlier work established that the single Tribolium homologue, Tc-disco, specified portions of the legs and other ventral appendages in this beetle (Patel et al., 2007). Further support for a conserved role comes from a report uncovering a possible link between a break in one of the human disco homologs, Basonuclin-2, and limb growth in humans (Bhoj et al., 2011). If this is indeed a causative mutation, then it is possible that the appendage role of the disco genes is conserved. Perhaps it is noteworthy as well that, given the role of $\mathrm{Hh}$ and disco in patterning Drosophila legs, Basonuclin is activated in some basal cell carcinomas by Gli proteins, the transcriptional responders of the Hh pathway (Cui et al., 2004). Indeed, future work will undoubtedly look to determine if there are such conserved roles and regulations.

\section{ACKNOWLEDGEMENTS}

We thank the TRiP at Harvard Medical School (NIH/NIGMS R01-GM084947) for providing transgenic RNAi fly stocks in this study. Stocks obtained from the Bloomington Drosophila Stock Center (NIH P40OD018537) were used in this study. We also thank the Vienna Drosophila Resource Center (Dietzl et al., 2007) for providing fly lines. We thank Dr. Patricia Estes for the GFP fly line and Dr. Stephen Cohen for the Tsh antibodies. The Dachshund monoclonal antibody, mAbdac2-3 deposited by G. M. Rubin was obtained from the Developmental Studies Hybridoma Bank, created by the NICHD of the NIH and maintained at The University of Iowa, Department of Biology, Iowa City, IA 52242. This work was supported by a grant (IOS-0842201) from the Developmental Mechanisms Program of the National Science Foundation (www.nsf.gov) to JWM. No competing interests declared.

AUTHOR CONTRIBUTIONS: JBR and JWM both developed the ideas, designed experiments and interpreted the data, and co-wrote the manuscript. 


\section{REFERENCES}

Angelini, D. R. and Kaufman, T. C. (2005). Insect appendages and comparative ontogenetics. Dev Biol 286, 57-77.

Basler, K. and Struhl, G. (1994). Compartment boundaries and the control of Drosophila limb pattern by hedgehog protein. Nature 368, 208-214.

Bhoj, E. J., Ramos, P., Baker, L. A., Garg, V., Cost, N., Nordenskjold, A., Elder, F. F., Bleyl, S. B., Bowles, N. E., Arrington, C. B., et al. (2011). Human balanced translocation and mouse gene inactivation implicate Basonuclin 2 in distal urethral development. European journal of human genetics : EJHG 19, 540546.

Bolinger, R. A. and Boekhoff-Falk, G. (2005). Distal-less functions in subdividing the Drosophila thoracic limb primordium. Dev Dyn 232, 801-816.

Brook, W. J. and Cohen, S. M. (1996). Antagonistic interactions between wingless and decapentaplegic responsible for dorsal-ventral pattern in the Drosophila Leg. Science 273, 1373-1377.

Brook, W. J., Diaz-Benjumea, F. J. and Cohen, S. M. (1996). Organizing spatial pattern in limb development. Annu Rev Cell Dev Biol 12, 161-180.

Calleja, M., Moreno, E., Pelaz, S. and Morata, G. (1996). Visualization of gene expression in living adult Drosophila. Science 274, 252-255.

Campbell, G., Weaver, T. and Tomlinson, A. (1993). Axis specification in the developing Drosophila appendage: the role of wingless, decapentaplegic, and the homeobox gene aristaless. Cell 74, 1113-1123.

Cohen, B., Simcox, A. A. and Cohen, S. M. (1993). Allocation of the thoracic imaginal primordia in the Drosophila embryo. Development 117, 597-608.

Cohen, B., Wimmer, E. A. and Cohen, S. M. (1991). Early development of leg and wing primordia in the Drosophila embryo. Mech Dev 33, 229-240.

Cohen, S. M. (1990). Specification of limb development in the Drosophila embryo by positional cues from segmentation genes. Nature 343, 173-177. 
Cui, C., Elsam, T., Tian, Q., Seykora, J. T., Grachtchouk, M., Dlugosz, A. and Tseng, H. (2004). Gli proteins up-regulate the expression of basonuclin in Basal cell carcinoma. Cancer research 64, 5651-5658.

Dey, B. K., Zhao, X. L., Popo-Ola, E. and Campos, A. R. (2009). Mutual regulation of the Drosophila disconnected (disco) and Distal-less (Dll) genes contributes to proximal-distal patterning of antenna and leg. Cell and tissue research $\mathbf{3 3 8}$, 227-240.

Diaz-Benjumea, F. J., Cohen, B. and Cohen, S. M. (1994). Cell interaction between compartments establishes the proximal-distal axis of Drosophila legs. Nature 372, 175-179.

Dietzl, G., Chen, D., Schnorrer, F., Su, K. C., Barinova, Y., Fellner, M., Gasser, B., Kinsey, K., Oppel, S., Scheiblauer, S., et al. (2007). A genome-wide transgenic RNAi library for conditional gene inactivation in Drosophila. Nature 448, 151-156.

Estella, C. and Mann, R. S. (2010). Non-redundant selector and growth-promoting functions of two sister genes, buttonhead and Sp1, in Drosophila leg development. PLoS genetics 6, e1001001.

Estella, C., McKay, D. J. and Mann, R. S. (2008). Molecular integration of wingless, decapentaplegic, and autoregulatory inputs into Distalless during Drosophila leg development. Dev Cell 14, 86-96.

Estella, C., Rieckhof, G., Calleja, M. and Morata, G. (2003). The role of buttonhead and Sp1 in the development of the ventral imaginal discs of Drosophila. Development 130, 5929-5941.

Estella, C., Voutev, R. and Mann, R. S. (2012). A dynamic network of morphogens and transcription factors patterns the fly leg. Curr Top Dev Biol 98, 173-198.

Fischbach, K. F. and Heisenberg, M. (1984). Neurogenetics and Behavior in Insects. J Exp Biol 112, 65-93.

Fristrom, D. and Fristrom, J. W. (1993). The Metamorphic Development of the Adult Epidermis. In The Development of Drosophila melanogaster (ed. M. Bate \& A. Martinez Arias). Plainview, N.Y.: Cold Spring Harbor Laboratory Press. 
Galindo, M. I., Bishop, S. A., Greig, S. and Couso, J. P. (2002). Leg patterning driven by proximal-distal interactions and EGFR signaling. Science 297, 256-259.

Galindo, M. I., Fernandez-Garza, D., Phillips, R. and Couso, J. P. (2011). Control of Distal-less expression in the Drosophila appendages by functional 3' enhancers. Dev Biol 353, 396-410.

Giorgianni, M. W. and Mann, R. S. (2011). Establishment of medial fates along the proximodistal axis of the Drosophila leg through direct activation of dachshund by Distalless. Dev Cell 20, 455-468.

Glossop, N. R. and Shepherd, D. (1998). Disconnected mutants show disruption to the central projections of proprioceptive neurons in Drosophila melanogaster. J Neurobiol 36, 337-347.

Gonzalez-Crespo, S., Abu-Shaar, M., Torres, M., Martinez, A. C., Mann, R. S. and Morata, G. (1998). Antagonism between extradenticle function and Hedgehog signalling in the developing limb. Nature 394, 196-200.

Gonzalez-Crespo, S. and Morata, G. (1996). Genetic evidence for the subdivision of the arthropod limb into coxopodite and telopodite. Development 122, 39213928.

Goto, S. and Hayashi, S. (1997). Specification of the embryonic limb primordium by graded activity of Decapentaplegic. Development 124, 125-132.

Grubbs, N., Leach, M., Su, X., Petrisko, T., Rosario, J. B. and Mahaffey, J. W. (2013). New components of Drosophila leg development identified through genome wide association studies. PloS one 8, e60261.

Hannah-Alava, A. (1958). Morphology and Chaetotaxy of the legs of Drosophila melanogaster. Journal of Morphology 103, 281-310.

Heffer, A., Grubbs, N., Mahaffey, J. and Pick, L. (2013). The evolving role of the orphan nuclear receptor ftz-f1, a pair-rule segmentation gene. Evol Dev 15, 406-417.

Heilig, J. S., Freeman, M., Laverty, T., Lee, K. J., Campos, A. R., Rubin, G. M. and Steller, H. (1991). Isolation and characterization of the disconnected gene of Drosophila melanogaster. Embo J 10, 809-815. 
Held, L. I., Jr. (2002). Bristles induce bracts via the EGFR pathway on Drosophila legs. Mech Dev 117, 225-234.

Jiang, J. and Struhl, G. (1996). Complementary and mutually exclusive activities of decapentaplegic and wingless organize axial patterning during Drosophila leg development. Cell 86, 401-409.

Juarez, M. T., Patterson, R. A., Sandoval-Guillen, E. and McGinnis, W. (2011). Duox, Flotillin-2, and Src42A are required to activate or delimit the spread of the transcriptional response to epidermal wounds in Drosophila. PLoS genetics 7, e1002424.

Knight, R. D. and Shimeld, S. M. (2001). Identification of conserved C2H2 zincfinger gene families in the Bilateria. Genome Biol 2, RESEARCH0016.

Kosman, D., Mizutani, C. M., Lemons, D., Cox, W. G., McGinnis, W. and Bier, E. (2004). Multiplex detection of RNA expression in Drosophila embryos. Science 305, 846.

Kubota, K., Goto, S., Eto, K. and Hayashi, S. (2000). EGF receptor attenuates Dpp signaling and helps to distinguish the wing and leg cell fates in Drosophila. Development 127, 3769-3776.

Kubota, K., Goto, S. and Hayashi, S. (2003). The role of Wg signaling in the patterning of embryonic leg primordium in Drosophila. Dev Biol 257, 117126.

Lecuit, T. and Cohen, S. M. (1997). Proximal-distal axis formation in the Drosophila leg. Nature 388, 139-145.

Lee, K. J., Freeman, M. and Steller, H. (1991). Expression of the disconnected gene during development of Drosophila melanogaster. Embo J 10, 817-826.

Mahaffey, J. W., Griswold, C. M. and Cao, Q. M. (2001). The Drosophila genes disconnected and disco-related are redundant with respect to larval head development and accumulation of mRNAs from deformed target genes. Genetics 157, 225-236.

Mardon, G., Solomon, N. M. and Rubin, G. M. (1994). dachshund encodes a nuclear protein required for normal eye and leg development in Drosophila. Development 120, 3473-3486. 
McClure, K. D. and Schubiger, G. (2005). Developmental analysis and squamous morphogenesis of the peripodial epithelium in Drosophila imaginal discs. Development 132, 5033-5042.

McGuire, S. E., Le, P. T., Osborn, A. J., Matsumoto, K. and Davis, R. L. (2003). Spatiotemporal rescue of memory dysfunction in Drosophila. Science 302, 1765-1768.

McKay, D. J., Estella, C. and Mann, R. S. (2009). The origins of the Drosophila leg revealed by the cis-regulatory architecture of the Distalless gene. Development 136, 61-71.

Milner, M., Bleasby, A. and Kelly, S. (1984). The role of the peripodial membrane of leg and wing imaginal discs ofDrosophila melanogaster during evagination and differentiation in vitro.

Mohler, J. (1988). Requirements for hedgehog, a segmental polarity gene, in patterning larval and adult cuticle of Drosophila. Genetics 120, 1061-1072.

Nègre, N., Brown, C. D., Ma, L., Bristow, C. A., Miller, S. W., Wagner, U., Kheradpour, P., Eaton, M. L., Loriaux, P., Sealfon, R., et al. (2011). A cisregulatory map of the Drosophila genome. Nature 471, 527-531.

O'Hara, E., Cohen, B., Cohen, S. M. and McGinnis, W. (1993). Distal-less is a downstream gene of Deformed required for ventral maxillary identity. Development 117, 847-856.

Panganiban, G. (2000a). Distal-less fuction during Drosophila appendage and sense organ development. Developmental Dynamics 218, 554-562.

Panganiban, G. (2000b). Distal-less function during Drosophila appendage and sense organ development. Dev Dyn 218, 554-562.

Patel, M., Farzana, L., Robertson, L. K., Hutchinson, J., Grubbs, N., Shepherd, M. N. and Mahaffey, J. W. (2007). The appendage role of insect disco genes and possible implications on the evolution of the maggot larval form. Dev Biol 309, 56-69.

Pederson, J. D., Kiehart, D. P. and Mahaffey, J. W. (1996). The role of HOM-C genes in segmental transformations: reexamination of the Drosophila Sex combs reduced embryonic phenotype. Dev Biol 180, 131-142. 
Raz, E. and Shilo, B. Z. (1993). Establishment of ventral cell fates in the Drosophila embryonic ectoderm requires DER, the EGF receptor homolog. Genes Dev 7, 1937-1948.

Rosenblatt, J., Raff, M. C. and Cramer, L. P. (2001). An epithelial cell destined for apoptosis signals its neighbors to extrude it by an actin- and myosindependent mechanism. Curr Biol 11, 1847-1857.

Ryder, E., Blows, F., Ashburner, M., Bautista-Llacer, R., Coulson, D., Drummond, J., Webster, J., Gubb, D., Gunton, N., Johnson, G., et al. (2004). The DrosDel collection: a set of P-element insertions for generating custom chromosomal aberrations in Drosophila melanogaster. Genetics 167, 797-813.

Schneider, C. A., Rasband, W. S. and Eliceiri, K. W. (2012). NIH Image to ImageJ: 25 years of image analysis. Nature methods 9, 671-675.

Schubiger, G., Schubiger, M. and Sustar, A. (2012). The three leg imaginal discs of Drosophila: "Vive la difference". Dev Biol 369, 76-90.

Steller, H., Fischbach, K. F. and Rubin, G. M. (1987). Disconnected: a locus required for neuronal pathway formation in the visual system of Drosophila. Cell 50, 1139-1153.

Tabata, T., Eaton, S. and Kornberg, T. B. (1992). The Drosophila hedgehog gene is expressed specifically in posterior compartment cells and is a target of engrailed regulation. Genes Dev 6, 2635-2645.

Tabata, T. and Kornberg, T. B. (1994). Hedgehog is a signaling protein with a key role in patterning Drosophila imaginal discs. Cell 76, 89-102.

Tautz, D. and Pfeifle, C. (1989). A non-radioactive in situ hybridization method for the localization of specific RNAs in Drosophila embryos reveals translational control of the segmentation gene hunchback. Chromosoma 98, 81-85.

Theisen, H., Haerry, T. E., O'Connor, M. B. and Marsh, J. L. (1996). Developmental territories created by mutual antagonism between Wingless and Decapentaplegic. Development 122, 3939-3948.

Tokunaga, C. (1962). Cell lineage and differentiation on the male foreleg of Drosophila melanogaster. Dev Biol 4, 489-516. 
Vachon, G., Cohen, B., Pfeifle, C., McGuffin, M. E., Botas, J. and Cohen, S. M.

(1992). Homeotic genes of the Bithorax complex repress limb development

in the abdomen of the Drosophila embryo through the target gene Distal-less.

Cell 71, 437-450. 


\section{TABLES}

Table 1: Analysis of disco $^{l}$ viability (from the total number of hatched embryos) comparing three different disco $^{1}$ lines.

\begin{tabular}{|c|c|c|c|c|}
\hline & Ore R & Bloomington & (C) & $w, f$ \\
\hline Collected & 200 & 200 & 200 & 200 \\
\hline Unfertilized/undeveloped & 19 & 33 & 7 & 14 \\
\hline Total number of developed eggs & 181 & 167 & 193 & 186 \\
\hline Dead embryos & 0 & 20 & 7 & 5 \\
\hline Dead Larvae & 6 & 22 & 20 & 12 \\
\hline Dead pupae & 2 & 33 & 13 & 11 \\
\hline $\begin{array}{c}\text { Eclosed } \\
(\% \text { of total \# fertilized eggs })\end{array}$ & 173 & 92 & 153 & 158 \\
$(95.6 \%)$ & $(55.1 \%)$ & $(79.3 \%)$ & $(84.9 \%)$ \\
\hline
\end{tabular}




\section{FIGURE LEGENDS}

Figure 1: Model of genetic specification of Drosophila leg development (adapted from that described by Lecuit and Cohen, 1997 and Giorgianni and Mann, 2011. (A) The segment polarity gene engrailed (en) is expressed in the cells of the posterior compartment of the leg disc and activates hedgehog ( $h h$, bright green). Cells anterior to the compartment boundary receiving Hh signal (arrowheads) activate decapentaplegic $(d p p)$ dorsally (orange) and wingless (wg) ventrally (blue). (B) In the center of the disc Distal-less ( $\mathrm{Dll})$ (dark green) is activated in response to high combined concentration of Wg and Dpp. Cells away from that center express dachshund (dac) and Dll (yellow) while further cells express only $d a c$ (red). Cells producing the most proximal structures and the body wall express teashirt (tsh) and homothorax (hth) (magenta). (C) Link between the adult structure and the corresponding genetic domains in the imaginal disc.

Figure 2: Phenotype of disco-lof pharate adults. (A-E) Ventral views of the flies, and (A'-E') close-up views of the corresponding ventral thorax. (A, A') Oregon R. In A' the wings and legs have been removed to expose the characteristic bristles (arrowheads) of the ventral thorax: $\mathrm{Sb}$, sternopleural bristles; $\mathrm{Mb}$, mesosternal bristle; $5 \mathrm{~b}$, the five small microchaetae along the ventral-anterior in the first thoracic segment. (B-E and B'-E') disco-lof flies (B) An example of Dll-Gal4 disco-lof pharate adult missing a first thoracic leg (asterisk in B') with enlargement of the proximal portion of the second and third legs. (C-C') Dll-Gal4 disco-lof pharate adult missing first and second thoracic legs (asterisks $\mathrm{C}^{\prime}$ ). A single bristle (arrowhead in C') remained near to where the second leg should have been. (D-D') Act-Gal4 disco-lof pharate adult. The first leg was reduced and the second and third legs were missing (asterisks in D'). Note that first thoracic leg maintained some tarsal structures including a few sex comb teeth. This was a hallmark of many Act-Gal4 disco-lof pharate adults. (E-E') The most extremely affected fly lacked most ventral identity. Only a single bristle remained (arrowhead in E').

Figure 3: Phenotype of disco-lof pharate adult legs. Prime letters are close-ups of the corresponding legs. (A) Wild type femur with both bracted and non-bracted bristles. In general, non-bracted bristles are characteristics of the proximal portion of the legs and 
extend usually into the proximal femur as shown here. More distal to this, bracted bristles are most prevalent, distally in the femur, tibia and tarsi. (B-C) Legs from pharate adults of Dll-Gal4 driving disco-lof and (D-E) Act-Gal4 driving disco-lof. In all cases, bracted and non-bracted bristles were intermixed in the remnants of the affected legs, though non-bracted bristles were the predominant type. Gray arrowheads point to examples of bractless bristles, and black arrowheads point to examples of bracted bristles. Note that the orientation of the bristle was also disrupted.

Figure 4: Morphology of disco-lof leg imaginal discs. (A) Leg disc of an Oregon R third instar larva. (B-E) A series of late third instar leg imaginal discs from Act-Gal4-driven disco-lof larvae. Note the variation in the sizes of the discs. (B) This leg disc was of a similar shape but somewhat reduced in size compared to that of the Oregon R (A). (C) This disc was about half the width of the Oregon R control and has a ventral protrusion, (arrowhead). (D and E) leg discs that were extremely reduced. In a severe case (E), the leg disc only reached a size slightly larger then the nerve entering the disc, which was still attached to the ventral nerve cord (VNC). (E') Note that this extremely reduced disc still accumulated Tsh protein (green) though we did not detect other discs determinants that we stained for (data not shown).

Figure 5: Analysis of leg gene determinants in Act-Gal4 disco-lof leg imaginal discs. We compared Tsh (green) and Dac (magenta) proteins and Dll transcript (red) accumulations between Oregon R and the disco-lof genotype using ImageJ (Schneider et al., 2012) to obtain estimations of fluorescence abundance (see materials and methods). The graph is in arbitrary units. Tsh measurements were nearly identical between the two genotypes, while Dac was reduced, but was just above significance cutoff of 0.05 . On the other hand, the difference in Dll RNA accumulation was statistically significant $(\mathrm{P}$-value $=0.00004)$ when compared to Oregon R.

Figure 6: Analysis of wingless transcript and protein accumulation in disco-lof leg imaginal discs. (A-A"') Oregon $\mathrm{R}$ leg disc stained to detect wg transcripts (green) and Wg protein (red). A'-A',' are enlargements of the marked area in A. (B-C',') Act-Gal4 
disco-lof discs. B'-B', are enlargements of the region marked in B. In disco-lof discs $w g$ transcripts appear to be more restricted (B') when compared to Oregon R (A'). The accumulation of $\mathrm{Wg}$ protein is likewise restricted, but also appears to be reduced (B', B',') when compares to Oregon R (A', A','). Note that in Oregon R, Wg protein spreads further than the area of transcript (A','), but this is not the case in the disco-lof discs (B",'). A more severely affected disco-lof third thoracic leg disc is shown in CC','(arrowhead). We did not detect wg RNA or protein in discs such as this, though both appeared normally in the wing and haltere. The DIC image shows the size relationship between the haltere (h), the wing discs (w) and the leg (white arrowhead) discs from the same third instar larva. Discs in A and B are oriented dorsal up and anterior to the left, while $\mathrm{C}$ have the posterior to the left. All magnifications were $20 \mathrm{X}$ except for $\mathrm{C}-\mathrm{C}$ ', which were $10 \mathrm{X}$ so as to include the haltere and wing for comparison.

Figure 7: TUNEL analysis of disco-lof leg discs. (A) Leg imaginal disc of an Oregon R fly. We detected one TUNEL-positive cell. (B) A nearly normal sized disco-lof leg disc. These discs had an increase in TUNEL staining, as did more severely affected leg discs (C). In both B and C many of the TUNEL positive cells were detected in the lumen of the discs.

Figure 8: disco and Dll transcript localizations in wild type Oregon R embryos at two different developmental stages. (A-A',') Embryos at stage 10/11, (B-B',') embryos at late stage 12. disco RNA is in red and Dll RNA in green. Prime letters indicate enlargements of the marked rectangles in A and B. Scale bar at $20 \mu \mathrm{m}$. During early embryogenesis (A-A',') disco (A', A' ') and Dll (A', A'"') transcripts were detected in the same groups of cells in the imaginal disc primordia. However, at the later stage (BB',') disco transcripts (B', B', were detected more broadly than Dll (B', B','), particularly noted toward the ventral portion of the leg disc primordia. Dorsal is up and anterior to the left.

Figure 9: $L T$ driven Beta-gal accumulation in wild type and $D f(1) E D 7355$ hemizygous embryos lacking disco and disco-r. In wild type embryos (A) LT drives Beta-gal 
accumulation in rings of cells in the thoracic segments marking cells of the leg imaginal disc primordia. In $D f(1) E D 7355$ hemizygous male embryos $(D f(1) E D 7355 / Y)$, only a few cells stained in each hemisegment, and they were not organized in rings. It is unknown whether these cells are true disc primordia cells or perhaps other cells in the region that activated $L T$. The identity of the $D f(1) E D 7355$ hemizygous embryos was confirmed by simultaneous detecting disco mRNA in the embryo collection, which was absent in the hemizygous embryos due to the deficiency. Dorsal is up and anterior to the left. 


\section{Figure 1}

A

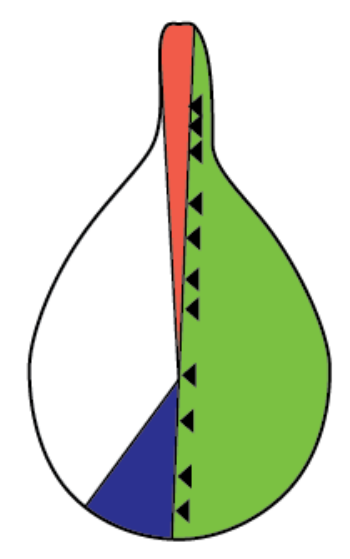

C

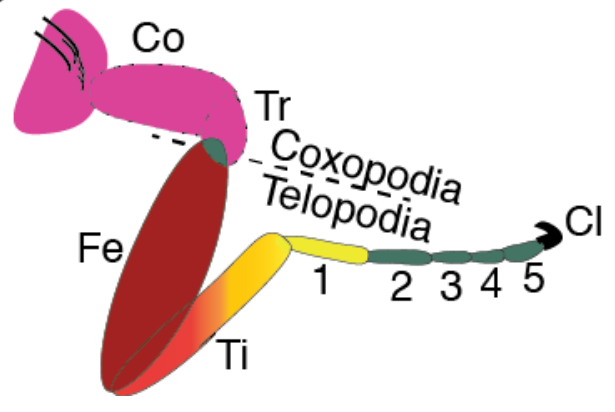

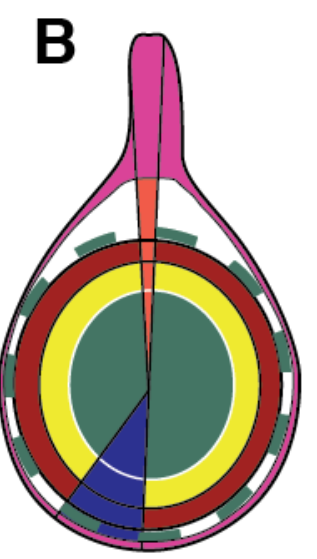

en $\& h h$

$\square \mathrm{wg}$

dpp

DII

DII \& dac

dac

tsh, hth \& exd 
bioRxiv preprint doi: https://doi.org/10.1101/052811; this version posted May 13, 2016. The copyright holder for this preprint (which was not certified by peer review) is the author/funder, who has granted bioRxiv a license to display the preprint in perpetuity. It is made available under aCC-BY-NC-ND 4.0 International license.

Figure 2

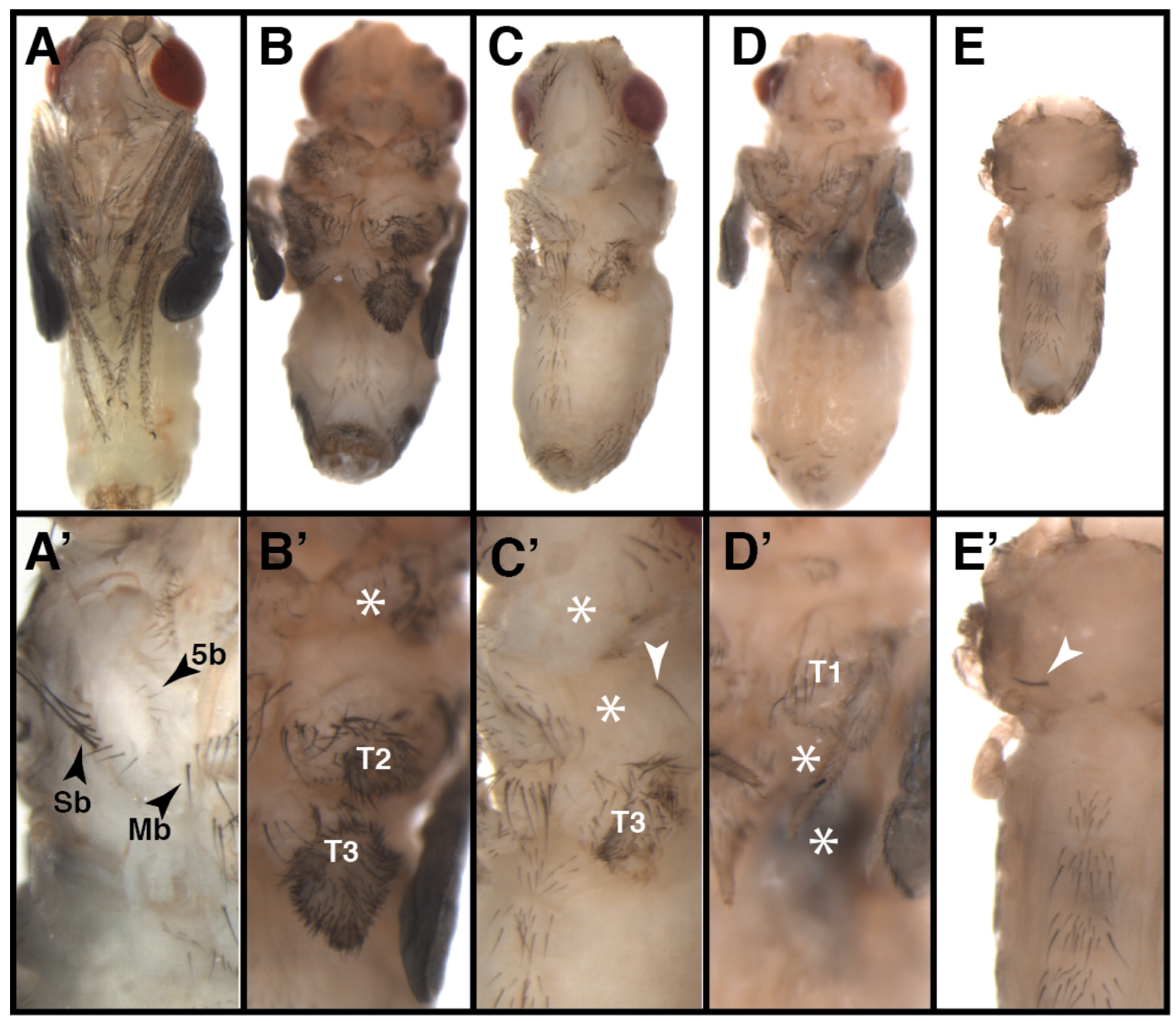


bioRxiv preprint doi: https://doi org/10.1101/052811; this version posted May 13,2016. The copyright holder for this preprint (which was not certified by peer review) is the author/funder, who has granted bioRxiv a license to display the preprint in perpetuity. It is made available under aCC-BY-NC-ND 4.0 International license.

\section{Figure 3}

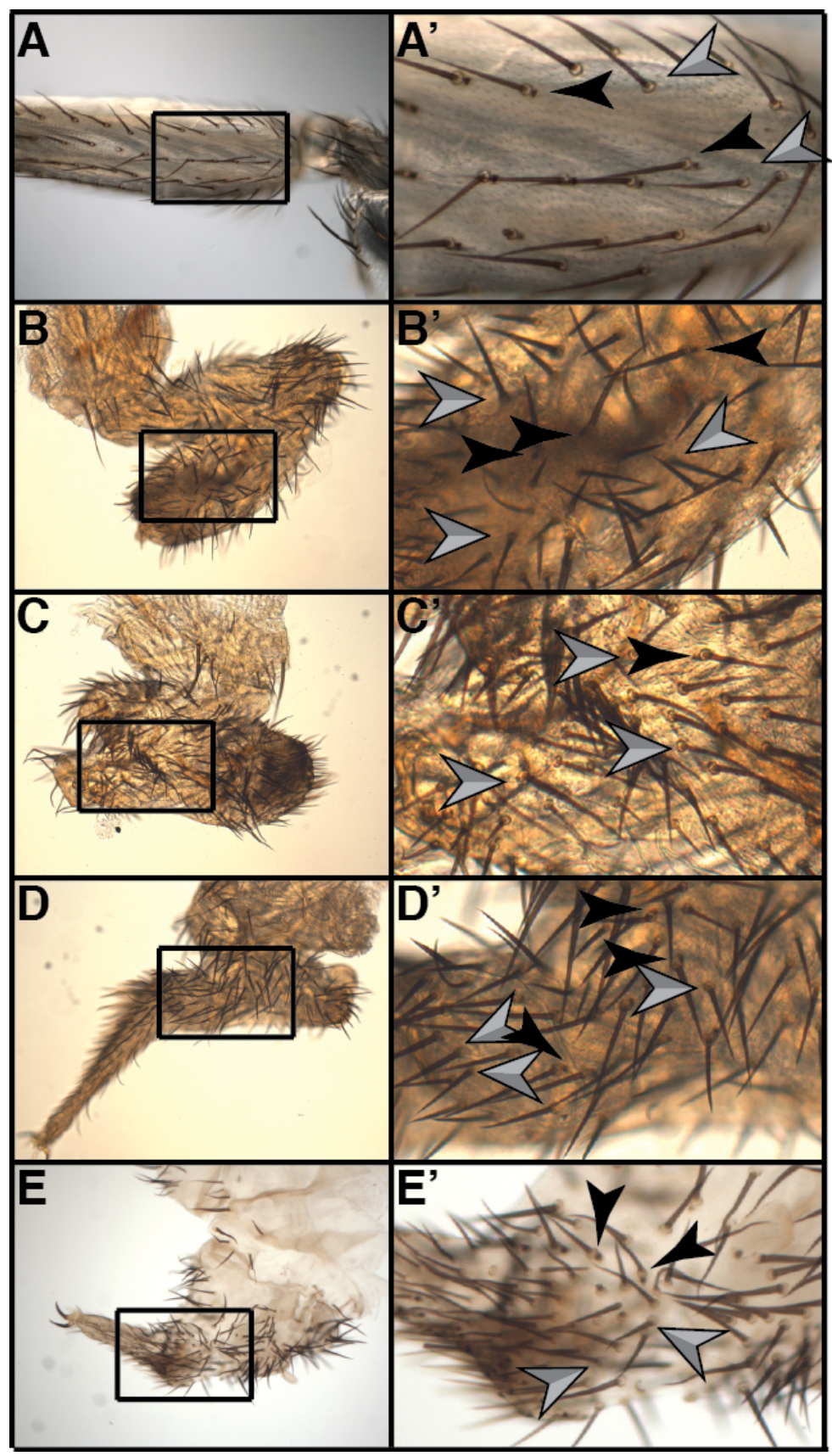


bioRxiv preprint doi: https://doi.org/10,1101/052811; this version posted May 13,2016 . The copyright holder for this preprint (which was not certified by peer review) is the author/funder, who has granted bioRxiv a license to display the preprint in perpetuity. It is made available under aCC-BY-NC-ND 4.0 International license.

\section{Figure 4}

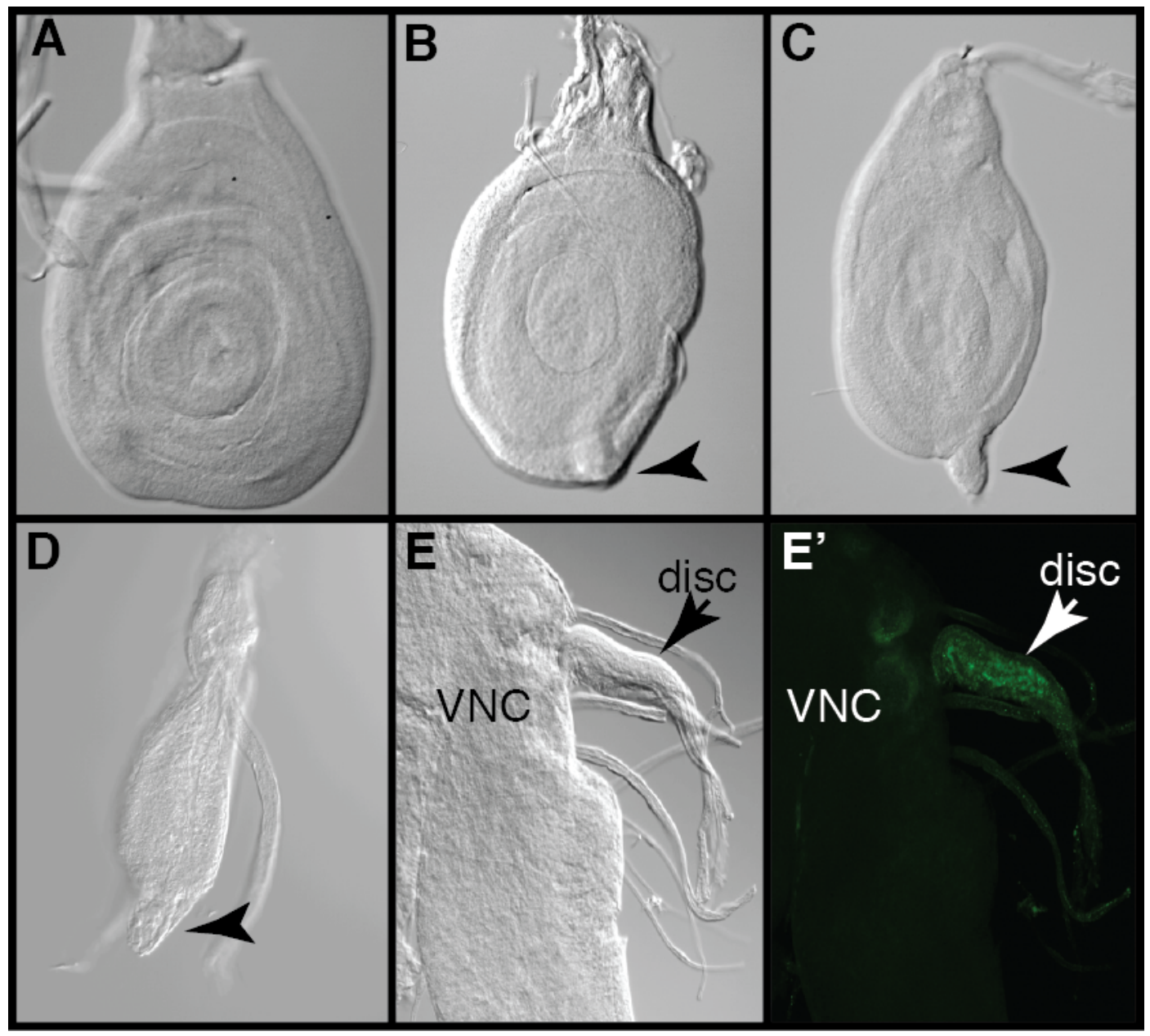




\section{Figure 5}

\section{Ore R}
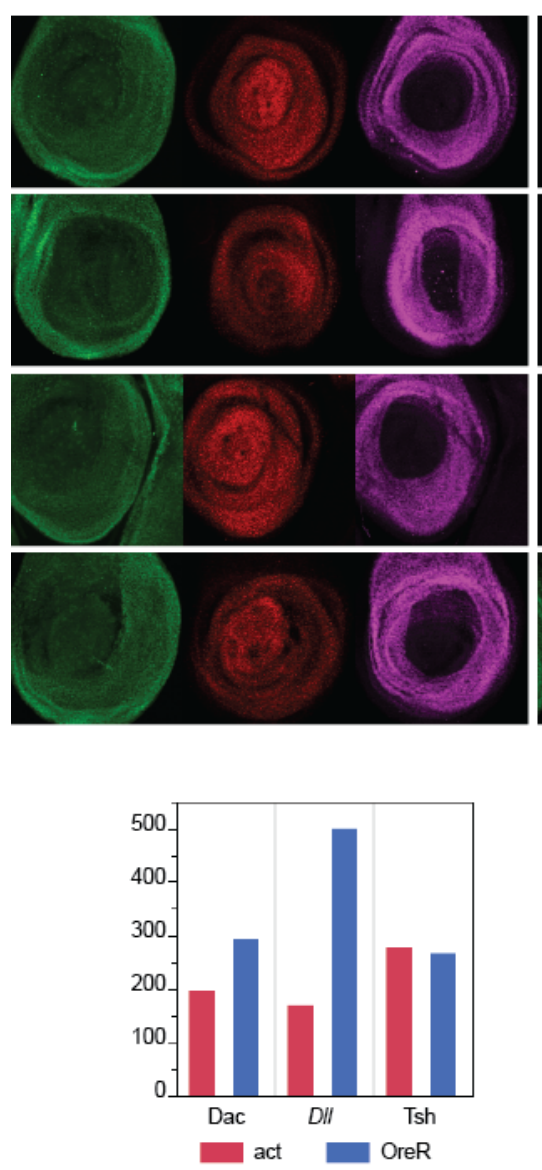

act-Gal4
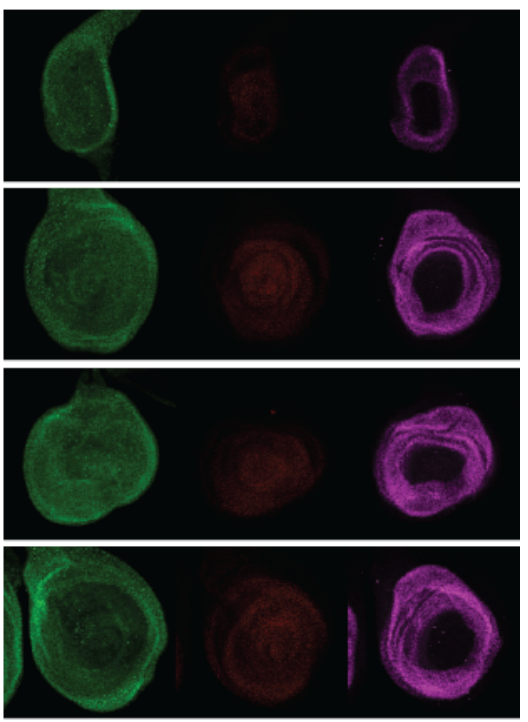

\begin{tabular}{ll} 
probe & $p$ value \\
DIl & 0.00004 \\
Dac & 0.06 \\
Tsh & 0.78 \\
\hline
\end{tabular}




\section{Figure 6}
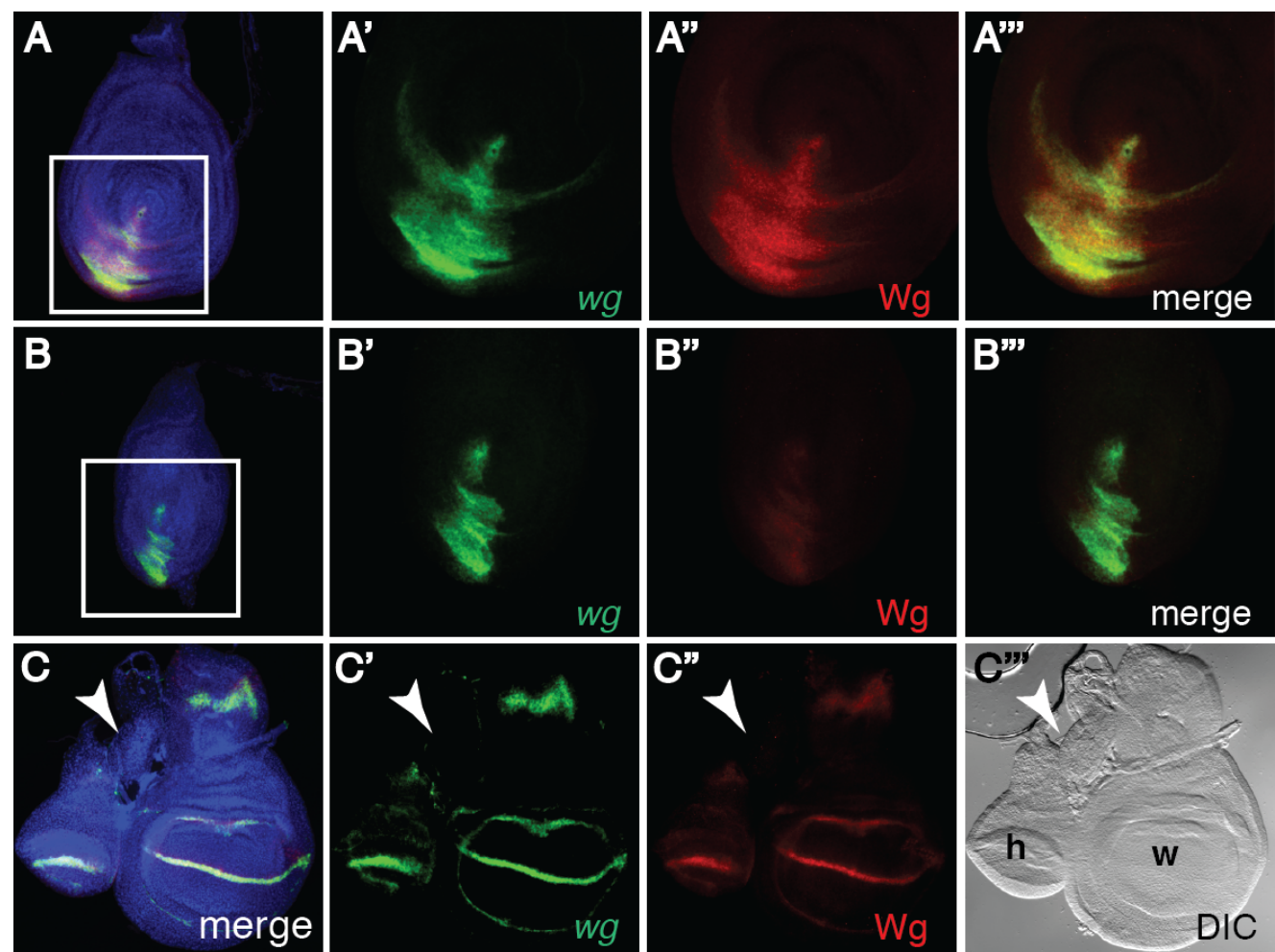

\section{Figure 7}

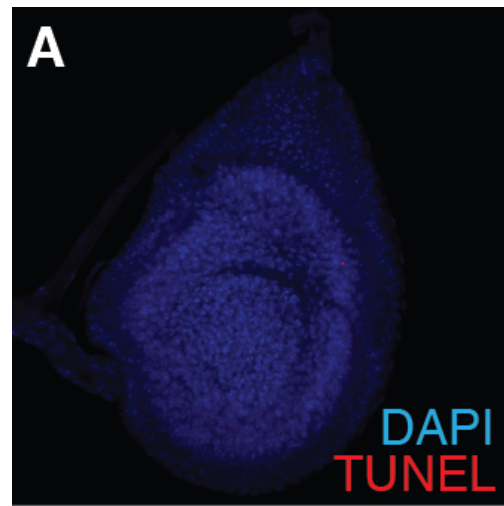

B

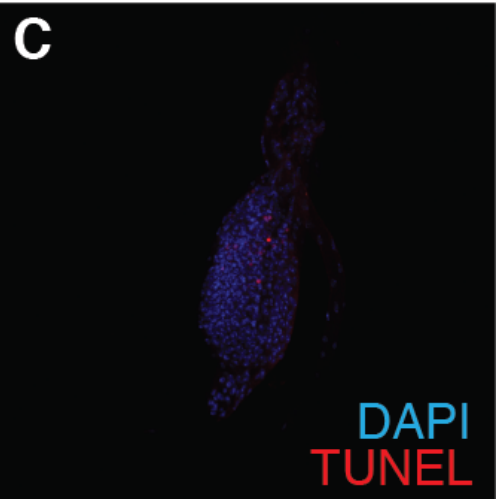


bioRxiv preprint doi: https://doi.org/10.1101/052811; this version posted May 13, 2016. The copyright holder for this preprint (which was not certified by peer review) is the author/funder, who has granted bioRxiv a license to display the preprint in perpetuity. It is made available under aCC-BY-NC-ND 4.0 International license.

\section{Figure 8}

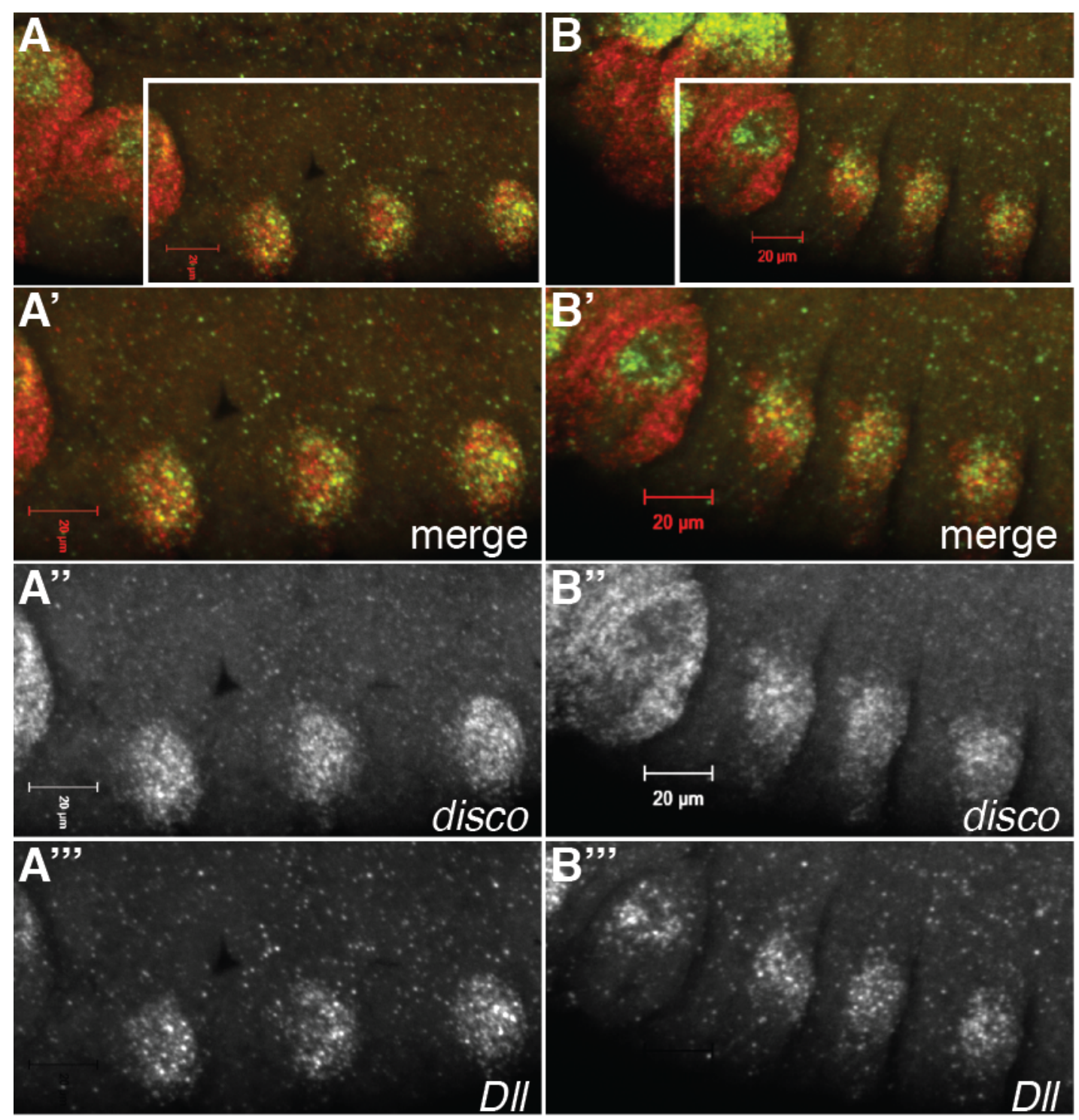


bioRxiv preprint doi: https://doi.org/10.1101/052811; this version posted May 13,2016 . The copyright holder for this preprint (which was not certified by peer review) is the author/funder, who has granted bioRxiv a license to display the preprint in perpetuity. It is made available under aCC-BY-NC-ND 4.0 International license.

\section{Figure 9}

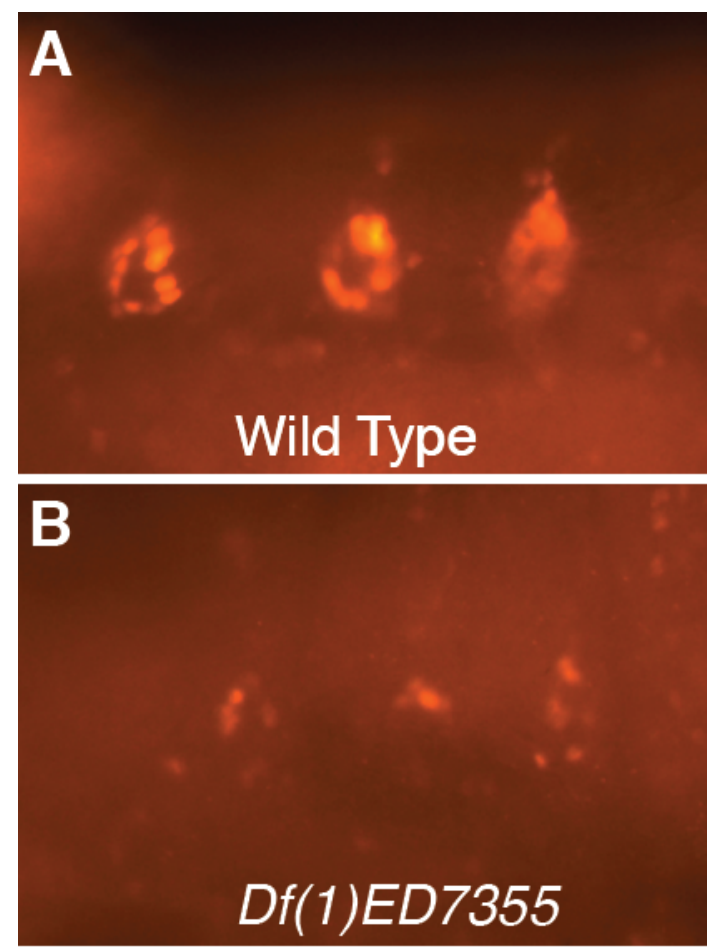

